\title{
Psychophysiological factors of adaptation in elite Paralympic sprint runners with visual impairments - a case study
}

\author{
DOI: https://doi.org/10.5114/pq.2018.79743
}

\author{
Zhanneta Kozina', Olena Chaika', Marian Cretu², Georgiy Korobeynikov³, Olena Repko', Irina Sobko', \\ Yurii Boichuk ${ }^{4}$, Natalia Tararak ${ }^{5}$, Andrii Osiptsov ${ }^{6}$, Mykola Trubchaninov ${ }^{7}$ \\ ${ }^{1}$ Department of Olympic and Professional Sport and Sport Games, H.S. Skovoroda Kharkiv National \\ Pedagogical University, Kharkiv, Ukraine \\ ${ }^{2}$ Faculty of Sciences, Physical Education and Informatics, University of Pitesti, Pitesti, Romania \\ ${ }^{3}$ Department of Biomechanics and Metrology of Sport, H.S. National University of Physical Education and Sports, \\ Kyiv, Ukraine \\ ${ }^{4}$ Department of Human Health and Correctional Education, H.S. Skovoroda Kharkiv National Pedagogical University, \\ Kharkiv, Ukraine \\ ${ }^{5}$ Department of Aesthetic Education, H.S. Skovoroda Kharkiv National Pedagogical University, Kharkiv, Ukraine \\ ${ }^{6}$ Department of Physical Education, Sport and Human Health Protection, Mariupol State University, Mariupol, Ukraine \\ ${ }^{7}$ Department of World History, H.S. Skovoroda Kharkiv National Pedagogical University, Kharkiv, Ukraine
}

\section{Abstract}

Introduction. The aim of the work was to determine the features of the influence of psychophysiological indices on the result in running for short distances of an elite sportswoman with visual impairments.

Methods. The study involved a high-qualified athlete specializing in short-distance running and long jump. Psychophysiological testing of the athlete took place with appropriate optical lenses. Individual characteristics of the psychophysiological state and results in running at $60 \mathrm{~m}, 80 \mathrm{~m}, 100 \mathrm{~m}, 120 \mathrm{~m}, 150 \mathrm{~m}$, and $200 \mathrm{~m}$ during 5 months of 2015 were analysed. Parameters characteristic for determining the psychophysiological state, typological characteristics of the nervous system, indicators of the nervous system working capacity, and attention indicators were analysed with the help of computer programs for psychophysiological testing. On the basis of the results in running and psychophysiological indicators, a factor analysis was carried out with the main components method with Varimax rotation, and multiple regression analysis by the linear model type in a step-by-step method.

Results. Four factors were identified in the individual structure of psychophysiological functions and effectiveness in running for short distances. Compensatory mechanisms of visual deficiency were identified maintaining high speed in short-distance running as psychophysiological functions, expressed as indicators characteristic of sprinters and specific indicators (efficiency, strength of the nervous system).

Conclusions. On the basis of mathematical models, the strengths of the athlete were highlighted, which tend to develop and also compensate for the inadequacy of the visual analyser.

Key words: sprint, track and field athletics, vision, limited possibilities, psychophysiological functions

\section{Introduction}




a branch of psychology that deals with the physiological bases of psychological processes. Although psychophysiology was a broad field of research in the 1960s and 1970s, it has now become quite specialized and branched into such narrow areas as social psychophysiology, cardiovascular psychophysiology, cognitive psychophysiology, and cognitive neuroscience. As noted by Cacioppo et al. [1], psychophysiology is closely related to the area of neuroscience which primarily relates to the relationship between psychological events and brain responses. Psychophysiology is also associated with a medical discipline known as psychosomatics [2-4].

Recently, psychophysiology has been referred to as the junction of psychological and medical science, and its popularity and importance have expanded in proportion to the implementation of the relationship between mind and body $[5,6]$. Within the framework of psychophysiology, certain areas are identified that are associated with the research of particularly important problems. Among these, there are: psychophysiology of sense organs, sensation, and perception; psychophysiology of the organization of movements; psychophysiology of activity; psychophysiology of arbitrary actions; psychophysiology of attention, memory, and learning; psychophysiology of speech and thinking; psychophysiology of motivation and emotions; psychophysiology of sleep; psychophysiology of stress; psychophysiology of functional states [7-9].

One of the methods applied in psychophysiology is mental chronometry [1, 2]. It consists in the use of response time in perception-movement problems to determine the content, duration, and temporal sequence of cognitive operations. Mental chronometry is one of the main paradigms of experimental and cognitive psychology and has found its place in

Correspondence address: Zhanneta Kozina, Department of Olympic and Professional Sport and Sport Games, H.S. Skovoroda Kharkiv National Pedagogical University, Altshevskih str. 29, Kharkiv, 61002, Ukraine, e-mail: zhanneta.kozina@gmail.com 
various disciplines, including cognitive psychophysiology, cognitive neuroscience, and behavioural neuroscience, in order to identify the mechanisms underlying cognitive processing [10-12].

Mental chronometry is studied with the measurement of reaction time, which is the time elapsed between the presentation of a sensory stimulus and the subsequent behavioural response [13-15]. The reaction time is limited not only by the signal transmission rate in the white matter, but also by the properties of synaptic and neuronal processing in cortical grey matter [16].

The response time is the sum of the reaction time and the time of motion. Usually, the research focuses on the reaction time. There are several methods of measurement: the time of a simple reaction, the time of a complex reaction, the reaction time to a moving object, and others [12, 13, 15].

Psychophysiological processes are important for the adaptation of the body to the effects of external and internal factors, since they reflect the work of the nervous system. In sports games, martial arts, the reaction speed increases. Also, the strength and mobility of the nervous system may increase [15-18].

The study of psychophysiological aspects of adaptation is typical of all sports. Of particular importance is the problem associated with the maximum manifestation of physical qualities, for example, in athletics. Currently, achievements in athletics are approaching the peak of human capabilities [19, 20], and the training process in the sport of higher achievements has reached the maximum values of volume and intensity of physical exertion [21, 22]. Therefore, the search for ways to improve the efficiency of the training process by optimizing it without increasing the volume and intensity of the loads, and also by taking into account and applying the training factors to enhance the sporting skills is of particular relevance. The disclosure of the physiological and psychophysiological factors of sporting achievements becomes especially topical.

Psychophysiological opportunities and typological features are inherent characteristics, and therefore belong to the main factors that determine the main aspects of sports success [15].

Psychophysiological indicators reflect the physiological manifestation of mental processes [15-18]. Among the psychophysiological indicators, the speed of a simple and complex reaction to light and sound stimuli occupies an important place. There are also methods for determining the properties of the nervous system by changing the rate of the complex reaction under various test conditions $[15,17$, 18]. The main properties of the nervous system are strength and mobility. Strength reflects resistance to strong shortterm stimuli, as well as to moderate long-acting stimuli. Mobility reflects the ability to switch from one object to another. In athletes in different sports, various properties of the nervous system prevail [15-18].

In a number of studies, the expediency of taking into account the psychophysiological capabilities of athletes was shown. This refers, for example, to their usefulness in determining individual fighting styles in martial arts [16] and the playing roles in sports games [12, 22]; also, the applicability of psychophysiological indicators in other sports has been shown [23, 24]. Psychophysiological opportunities also affect success in running. Several studies $[16,18,25,26]$ proved that sprinters were usually characterized by high mobility of the nervous system and not high strength of the nervous system. For marathoners, on the contrary, high strength of studies of psychophysiological capabilities of runners with visual impairments have not been conducted.

It is possible that in the case of athletes with visual impairments, the impact of psychophysiological possibilities is not the same as in healthy athletes, but they have certain characteristics. In disabled athletes, the work of the nervous system is aimed at achieving the motor task and compensating for missing functions. Therefore, their psychophysiological abilities and properties of the nervous system may differ from those in healthy athletes. Since psychophysiological factors play an important role in achieving success in sports, an significant problem is the identification of the psychophysiological features of athletes with visual impairments, especially those participating in short-distance running. Ilin [18] showed that healthy sprinters were characterized by high mobility of the nervous system, high reaction speed, but not high strength of the nervous system. Is this also true of athletes with visual impairments? Or do sprinters with visual impairments have other psychophysiological indicators that differ from those of healthy athletes? The psychophysiological functions of sprinters with visual impairments should participate in the work of the nervous system in compensating for missing functions.

Therefore, in this study, the aim was set to determine the features of the influence of psychophysiological indices on the result in running for short distances of an elite sportswoman with visual impairments.

\section{Subjects and methods}

\section{Subjects}

Only 1 athlete participated in this study. The subject was tested many times during 5 months. The woman specializes in short-distance running and long jump; she was the European Athletics Champion 2010, prize winner of the World Paralympic and Paralympic Games among athletes with visual impairments (T12 category) in 2016. T12 is a category of athletes disabled because of a visual impairment. All athletes with disabilities are classified according to the impairment degree. The examined athlete belongs to T12 category as she manifests a visual impairment associated with a retinal disorder. However, with powerful lenses she can run, work at a computer, etc. [10].

The psychophysiological testing of the athlete took place highly close to a computer screen. The study was conducted for 5 months. Twice a week, psychophysiological indicators and running speed were determined. Thus, 36 tests of one athlete were performed.

\section{Experimental protocol}

Different reaction parameters were measured. An image appeared on a monitor screen and it was necessary to press the mouse button as soon as possible. After the tests at the training, the participant ran through segments of different distances. With the help of mathematical processing, the influence of the psychophysiological state on the result in running was revealed.

The athlete's results obtained in years 1997-2015 were analysed. With mathematical data processing, a forecast for 2016 was built. After the Paralympic Games in 2016, the athlete's results were compared with the forecast.

Individual characteristics of the psychophysiological state and results in running at $60 \mathrm{~m}, 80 \mathrm{~m}, 100 \mathrm{~m}, 120 \mathrm{~m}, 150 \mathrm{~m}$, and $200 \mathrm{~m}$ during 5 months of 2015 were analysed. 
The results in the race were recorded in training, as well as in official and unofficial competitions. The total of 36 results were analysed. One day before the start, psychophysiological indicators were recorded with the use of the Psychodiagnostics computer program and similar programs for psychophysiological testing.

Psychophysiological research methods were used to determine the level of attention, ability to concentrate, mental performance, and the speed of reaction. Research of mental working capacity was conducted with the method of Schulte table (Schulte video test). The ability to concentrate was studied with the proof-reading (correction) method (Bourdon test) (Burdon video test).

The following parameters characteristic of the psychophysiological state, typological features of the nervous system, indicators of the nervous system efficiency, and attention indicators [8] have been set:

- A set of indices for the time of a simple visual-motor reaction (mean of 30 attempts [ms], standard deviation [ms], number of errors); duration of exposure (signal) - $900 \mathrm{~ms}$.

- A set of indicators of a complex visual-motor reaction of selecting 1 element from 3 and selecting 2 elements from 3 (mean value of 30 attempts [ms], standard deviation [ms], number of errors); duration of exposure (signal) - $900 \mathrm{~ms}$.

- A set of indicators of a complex visual-motor reaction of selecting 2 elements out of 3 in the feedback mode, i.e. as the response time changes, the signal delivery time changes. The 'short version' is carried out in the feedback mode, when the duration of exposure changes automatically depending on the response of the subject: after a correct answer, the duration of the next signal is reduced by $20 \mathrm{~ms}$, and after a wrong one, it increases by the same amount. The range of the signal exposure change during the test subject's operation is $20-900 \mathrm{~ms}$, with a pause between exposures of $200 \mathrm{~ms}$. The correct answer is to press the left (right) mouse button while displaying a certain exposure (image), or during a pause after the current exposure. In this test, the time to reach the minimum exposure of the signal and the time of the minimum exposure of the signal reflect the functional mobility of the nervous processes; the number of errors reflects the strength of the nervous processes (the lower these parameters, the higher the mobility and strength of the nervous system). The duration of the initial exposure is $900 \mathrm{~ms}$; the amount of change in the duration of the signals with correct or erroneous responses is $20 \mathrm{~ms}$; pause between the presentation of signals $-200 \mathrm{~ms}$; the number of signals is 50 . The indicators are fixed: the average value of the latent period (ms); root mean square deviation (ms); number of mistakes; time of test execution (s); minimum exposure time (ms); time of exposure to the minimum exposure (s).

- A set of indicators of a complex visual-motor reaction of selecting 2 elements out of 3 in the feedback mode, i.e. as the response time changes, the signal delivery time changes. The 'long version' is carried out in the feedback mode, when the duration of exposure changes automatically depending on the response of the subject: after a correct answer, the duration of the next signal is reduced by $20 \mathrm{~ms}$, and after a wrong one, it increases by the same amount. The range of the signal exposure change during the test subject's operation is $20-900 \mathrm{~ms}$, with a pause between exposures of 200 ms. The correct answer is to press the left (right) mouse button while displaying a certain exposure (image), or during a pause after the current exposure. In this test, the time to reach the minimum exposure of the signal and the time of the minimum exposure of the signal reflect the functional mobility of the nervous processes; the number of errors reflects the strength of the nervous processes (the lower these parameters, the higher the mobility and strength of the nervous system). In addition, the total time of the test reflects a combination of strength and mobility of the nervous processes. The duration of the initial exposure is $900 \mathrm{~ms}$; the amount of change in the duration of the signals with correct or erroneous responses is $20 \mathrm{~ms}$; pause between the presentation of signals $-200 \mathrm{~ms}$; the number of signals is 120 . The indicators are fixed: the average value of the latent period (ms); root mean square deviation (ms); number of mistakes; time of test execution (s); minimum exposure time (ms); time of exposure to the minimum exposure (s).

The indicators of mental working capacity were also determined in accordance with the Schulte test. In this test, the subject needs $5 \times 5$ tables of 25 digits (from 1 to 25 ) arranged in a random order, to mark the numbers from 1 to 25 . After passing the first table, the second with a different order of digits immediately appears, and so on. In total, the subject passes 5 tables. The reported outcomes were: the time of work on each of the 5 tables (min), the efficiency of work as the arithmetic average of the time of operation on 5 tables (min), the performance of the nervous system as a private time of work on the $4^{\text {th }}$ and $1^{\text {st }}$ tables, and the workability of the nervous system as a private work time for the $2^{\text {nd }}$ and $1^{\text {st }}$ tables.

To determine the attention indicators, the Bourdon test was used. In this test, you are to mark a specific letter in a table with letters. The test results are evaluated in accordance with the following indicators: number of errors, time of the test.

The response time of the selection for the signals appearing at various points of the screen in a button selection program ('Ermakov test') was also determined.

The dynamics of the competitive performance of a highqualified athlete at international competitions from 1997 to 2015 in the 400m, 200m, 100m, and 60m races was analysed. Mathematical models of non-linear regression describing the dynamics of the athlete's competitive performance in the long-term period were compiled. On the basis of the obtained models, a forecast of the results for 2016-2017 was developed. Models of competitive performance as nonlinear sinusoidal regression in the annual cycle of preparation for the Paralympic Games of 2016 among athletes with visual impairments (T12 category) were prepared. Recommendations were given for adjusting the training process in accordance with the obtained natural patterns of changes in the functional state of the athlete. The competitive performance of the athlete in 2016 was compared with the forecasted results.

\section{Statistical analysis}

On the basis of the results in the run and psychophysiological indicators, a factor analysis was carried out with the method of main components with Varimax rotation with Kaiser normalization and the usage of the SPSS program.

The results in running at $100 \mathrm{~m}$ and $200 \mathrm{~m}$, and psychophysiological indicators were employed in a multiple regression analysis by the type of the linear model in a step-bystep method with the use of the SPSS and Excel programs. The dynamics of the competitive performance of a highqualified female athlete at international competitions from 1997 to 2015 in running at $200 \mathrm{~m}$ and $100 \mathrm{~m}$ was analysed. 


\section{Ethical approval}

The research related to human use has been complied with all the relevant national regulations and institutional policies, has followed the tenets of the Declaration of Helsinki, and has been approved by the authors' institutional review board.

\section{Informed consent}

Informed consent has been obtained from the participant included in this study.

\section{Results}

The results of factor analysis showed that the number of factors whose eigenvalue was greater than 1 was equal to 10 . At the same time, on the chiselled diagram of the ei- genvalues of the factors, which is also called a scree plot, we can distinguish 4 main factors that form the so-called slope in the diagram.

Thus, 4 main factors were identified; the percentage with regard to the total dispersion was $46.4 \%$ for the $1^{\text {st }}$ factor, $8.2 \%$ for the $2^{\text {nd }}$ factor, $6.8 \%$ for the $3^{\text {rd }}$ factor, $5.1 \%$ for the $4^{\text {th }}$ factor, and $34 \%$ for the other factors.

Table 1 presents the results of combining the recorded indicators into groups by means of factor analysis by the principal component method. On the basis of the indicators that formed each group (factor), the names of the factors were given.

The $1^{\text {st }}$ factor included such indicators as the effectiveness of work in the Schulte test, the time of work on the $1^{\text {st }}$, $2^{\text {nd }}, 3^{\text {rd }}, 4^{\text {th }}, 5^{\text {th }}$ tables of Schulte, the total time and performance of the nervous system according to the Schulte test,

Table 1. The matrix of the factor analysis components after rotation in accordance with the Varimax method of the indices of the psychophysiological state and the results in the run of the elite athlete with a visual impairment (the number of tests, 36; the number of factors included, 27 out of 43 )

\begin{tabular}{|c|c|c|c|c|}
\hline \multirow[b]{2}{*}{ Indicators } & \multicolumn{4}{|c|}{ Factors } \\
\hline & $\begin{array}{c}1 \\
46 \%\end{array}$ & $\begin{array}{c}2 \\
8 \%\end{array}$ & $\begin{array}{c}3 \\
7 \%\end{array}$ & $\begin{array}{c}4 \\
5 \%\end{array}$ \\
\hline Effectiveness of work in the Schulte test (min) & $0.993^{*}$ & & & \\
\hline Operating time on the $4^{\text {th }}$ Schulte table ( $\mathrm{min}$ ) & 0.992 & & & \\
\hline Working time on the $5^{\text {th }}$ Schulte table $(\mathrm{min})$ & 0.988 & & & \\
\hline Working time on the $2^{\text {nd }}$ Schulte table (min) & 0.985 & & & \\
\hline Working time on the $3^{\text {rd }}$ Schulte table (min) & 0.983 & & & \\
\hline Working time in the Bourdon test (min) & 0.983 & & & \\
\hline Functionality of the nervous system according to the Schulte test (cu) & 0.98 & & & \\
\hline Time of a simple visual-motor reaction (ms) & 0.96 & & & \\
\hline Operating time on the $1^{\text {st }}$ Schulte table ( $\mathrm{min}$ ) & 0.958 & & & \\
\hline Response time of selecting 1 element from $3(\mathrm{~ms})$ & 0.94 & & & \\
\hline Running 100 m (s) & 0.935 & & & \\
\hline Total working time for the Schulte test (min) & 0.892 & & & \\
\hline Running 150 m (s) & 0.885 & & & \\
\hline Running $60 \mathrm{~m}(\mathrm{~s})$ & 0.883 & & & \\
\hline Minimum exposure time of the signal in the test with feedback at 120 signals (ms) & 0.835 & & & \\
\hline Total test execution time with feedback at 120 signals (s) & 0.816 & & & \\
\hline Total test execution time with feedback at 30 signals (s) & 0.807 & -0.408 & & \\
\hline Running 200 m (s) & 0.794 & & & \\
\hline Running $80 \mathrm{~m}$ (s) & 0.644 & & & \\
\hline 'Ermakov test' (number of correct answers for $15 \mathrm{~s}$ ) & 0.627 & -0.414 & & \\
\hline Response time in the feedback test at 30 signals (ms) & & 0.866 & & \\
\hline Running 120 m (s) & 0.577 & 0.737 & & \\
\hline Response time of the selection of 2 elements of $3(\mathrm{~ms})$ & & 0.716 & & \\
\hline Test for the response time of the selection of 2 elements of 3 (number of errors) & & & 0.882 & \\
\hline Test for a simple visual-motor reaction (number of errors) & & & 0.75 & \\
\hline Mean square deviation in the test for the response time of the selection of 1 element of $3(\mathrm{~ms})$ & & & & 0.932 \\
\hline Mean square deviation in the test with feedback at 120 signals (ms) & & & & 0.793 \\
\hline
\end{tabular}

* The correlation coefficients between the test scores and factors are only greater than 0.4 . 
Table 2. Coefficients of multiple regression equations with incremental involvement of indicators in running on $100 \mathrm{~m}$ in the athlete with a visual impairment (number of measurements, 36)

\begin{tabular}{|c|c|c|c|c|c|c|}
\hline \multirow{2}{*}{ Model } & \multirow{2}{*}{$\begin{array}{l}\text { Coefficients with variable } \\
\text { regression equations }\end{array}$} & \multicolumn{2}{|c|}{ Non-standardized coefficients } & \multirow{2}{*}{$\frac{\text { Standardized coefficients }}{\text { Beta }}$} & \multirow{2}{*}{$t$} & \multirow{2}{*}{$p$} \\
\hline & & B & Standard error & & & \\
\hline \multirow{2}{*}{1} & Constant & 2.765 & 0.433 & & 6.388 & 0.000 \\
\hline & SVMR (ms) & 0.04 & 0.002 & 0.966 & 21.836 & 0.000 \\
\hline \multirow{3}{*}{2} & Constant & 1.824 & 0.444 & & 4.109 & 0.000 \\
\hline & SVMR (ms) & 0.032 & 0.003 & 0.77 & 12.012 & 0.000 \\
\hline & MSE_120 (ms) & 0.007 & 0.002 & 0.242 & 3.771 & 0.001 \\
\hline \multirow{4}{*}{3} & Constant & -0.793 & 0.862 & & -0.92 & 0.365 \\
\hline & SVMR (ms) & 0.033 & 0.002 & 0.815 & 14.208 & 0.000 \\
\hline & MSE_120 (ms) & 0.006 & 0.002 & 0.2 & 3.503 & 0.001 \\
\hline & MSE_30 (ms) & 0.006 & 0.002 & 0.114 & 3.396 & 0.002 \\
\hline \multirow{5}{*}{4} & Constant & 1.521 & 1.152 & & 1.321 & 0.196 \\
\hline & SVMR (ms) & 0.033 & 0.002 & 0.807 & 15.4 & 0.000 \\
\hline & MSE_120 (ms) & 0.006 & 0.002 & 0.185 & 3.536 & 0.001 \\
\hline & MSE_30 (ms) & 0.006 & 0.002 & 0.104 & 3.351 & 0.002 \\
\hline & $\mathrm{ChR}(\mathrm{ms})$ & -0.004 & 0.002 & 0.086 & 2.748 & 0.01 \\
\hline \multirow{6}{*}{5} & Constant & 5.808 & 1.999 & & 2.905 & 0.007 \\
\hline & SVMR (ms) & 0.019 & 0.006 & 0.47 & 3.318 & 0.002 \\
\hline & MSE_120 (ms) & 0.001 & 0.002 & 0.033 & 0.433 & 0.668 \\
\hline & MSE_30 (ms) & 0.006 & 0.002 & 0.12 & 4.1 & 0.000 \\
\hline & $\mathrm{ChR}(\mathrm{ms})$ & -0.006 & 0.002 & 0.118 & 3.749 & 0.001 \\
\hline & Shul_3 (min) & 2.09 & 0.826 & 0.468 & 2.531 & 0.017 \\
\hline \multirow{5}{*}{6} & Constant & 6.413 & 1.414 & & 4.535 & 0.000 \\
\hline & SVMR (ms) & 0.018 & 0.005 & 0.436 & 3.759 & 0.001 \\
\hline & MSE_30 (ms) & 0.007 & 0.001 & 0.124 & 4.48 & 0.000 \\
\hline & $\mathrm{ChR}(\mathrm{ms})$ & -0.006 & 0.001 & 0.123 & 4.28 & 0.000 \\
\hline & ScT_3 (min) & 2.369 & 0.511 & 0.53 & 4.633 & 0.000 \\
\hline
\end{tabular}

SVMR - time of a simple visual-motor reaction, the average value for one test of 30 signals (time of a simple visual-motor reaction) MSE_120 - time of the minimum exposure of the signal in the test with feedback at 120 signals (minimum signal exposure) MSE_30 - time of the minimum exposure of the signal in the test with feedback at 30 signals (minimum signal exposure) $\mathrm{ChR}$ - reaction time of the choice of 2 signals of 3 (choice reaction)

ScT_3 - time of work on the third table in the Schulte test (Schulte table)

the time of work in the Bourdon test, motor reaction time, the response time of selecting 1 element of 3 , the minimum exposure time of the signal in the feedback test at 120 signals, the total test execution time with feedback at 120 signals, the total test execution time with feedback at 30 signals; the running time of segments of $60 \mathrm{~m}, 80 \mathrm{~m}, 100 \mathrm{~m}, 150 \mathrm{~m}$, $200 \mathrm{~m}$, the number of correct responses to signals in the 'Ermakov test' (Table 2). Thus, the $1^{\text {st }}$ factor included the results of running through practically all segments, the psychophysiological indices associated with the time of simple reaction, the mobility of the nervous system (the minimum exposure time of the signal), as well as the performance of the nervous system (Schulte test results, overall test time with feedback). On the basis of indicators that were included in the $1^{\text {st }}$ factor, the name 'Fast work capacity' was given to the $1^{\text {st }}$ factor.

The $2^{\text {nd }}$ factor included the following indicators: the response time of the selection of 2 elements of 3 and the running time of the segment of $120 \mathrm{~m}$ (Table 2). On the basis of these indicators, the $2^{\text {nd }}$ factor was called 'Complicated reaction'.

The $3^{\text {rd }}$ factor included indicators of the number of errors in the test at the time of the reaction of selecting 2 elements out of 3 and the number of errors in the test for a simple visual-motor reaction (Table 1). On the basis of these indicators, the $3^{\text {rd }}$ factor was called 'Attention'.
The $4^{\text {th }}$ factor included such indicators as the standard deviation in the test for the reaction time of the selection of 1 element of 3 and the standard deviation in the test with feedback at 120 signals (Table 1). On the basis of these indicators, the $4^{\text {th }}$ factor was called 'Stability'.

To reveal the degree of influence of psychophysiological functions on the athletic result in running on $100 \mathrm{~m}$ and $200 \mathrm{~m}$, multiple regression analysis was performed by a step-by-step method, which allows one to involve the analysed indicators in the model in turn (Table 2). On the basis of the results of the analysis of the coefficients in the obtained multiple regression model to describe the influence of psychophysiological functions at the time of running a $100 \mathrm{~m}$ in the case of the elite athlete with a visual impairment, we chose the $5^{\text {th }}$ model because it contained 5 figures (the largest number of all received models) with significant coefficients and the presence of a 2-factor with beta values greater than 0.4 . As a result, the following regression equation was obtained:

$y=5.808+0.019 x_{1}+0.001 x_{2}+0.006 x_{3}-0.006 x_{4}+2.09 x_{5}(1)$

where:

$y$ - running time of an elite athlete with a visual impairment of $100 \mathrm{~m}$;

$\mathrm{x}_{1}$ - time of simple visual-motor reaction (ms); 
$\mathrm{x}_{2}$ - time of the minimum exposure of the signal in the test with feedback at 120 signals (ms);

$x_{3}$ - time of the minimum exposure of the signal in the test with feedback at 30 signals (ms);

$\mathrm{x}_{4}$ - response time of the selection of 2 signals from $3(\mathrm{~ms})$;

$\mathrm{x}_{5}$ - time of work on the third table in the Schulte test ( $\mathrm{min}$ ).

Substituting the average values of the results of psychophysiological testing of the athlete (Table 3 ) in this equation, we obtain:

Run_100 m (s) $=5.808+0.019 \cdot 238.08+0.001 \cdot 383.31+$

$0.006 \cdot 434.22-0.006 \cdot 435.81+2.09 \cdot 0.52$

Run_100 m (s) = 11.79

Similarly, the effect of psychophysiological indices on the running time of a distance of $200 \mathrm{~m}$ was analysed. As a result, the following regression equation was obtained:

$y=10.13+0.045 x_{1}+0.017 x_{2}+0.001 x_{3}+0.008 x_{4}$

where:

$y$ - elapsed time of the elite athlete with a visual impairment at $200 \mathrm{~m}$;

$\mathrm{x}_{1}$ - time of a simple visual-motor reaction (mean time of minimum exposure for the minimum exposure of the signal in the test with feedback at 120 signals) (ms);

$\mathrm{x}_{2}$ - total test execution time with feedback at 120 signals (s) (ms);

$\mathrm{x}_{3}$ - time of the output to the minimum exposure of the signal in the test with feedback at 30 signals (s);

$\mathrm{x}_{4}$ - time to reach the minimum exposure of the signal in the test with feedback at 120 signals (s).

Substituting the average values of the results of psychophysiological testing of the athlete (Table 2 ) in this equation, we obtain:

Run_200 m (s) $=10.13+0.045 \cdot 238.08+0.017 \cdot 279.56+$ $0.001 \cdot 75.83+0.008 \cdot 66.17$

Run_200 m (s) $=26.20$
Thus, on the basis of factor analysis, multiple regression of the indicators of the psychophysiological state, results in running for short distances, regression models of performance, and analysis of the predicted result at different distances, the athlete's strengths were highlighted which tend to develop. Such strengths are explosive force, starting speed, speed endurance. Of the psychophysiological characteristics, the strengths of the reaction are the speed, mobility, and strength of the nervous system. Apparently, in this case, the strength of the nervous system acts as a compensatory factor of limited visual possibilities, since it is not a typical characteristic of a sprinter. Owing to the received data, practical recommendations were given for the preparation of the athlete for the Paralympic Games of 2016.

\section{Discussion}

In this study, the aim was to identify the features of the influence of psychophysiological indicators on the result of running for short distances of an elite athlete with visual impairments.

As a result of factor analysis with the main component method, it was revealed that the majority of psychophysiological indicators entered into one, the $1^{\text {st }}$ factor, which amounted to $46 \%$ of the total variance. This indicates a highly structured work of the body in the athlete of high qualifications. Similar data were obtained by us earlier in studies of the structure of the preparedness of basketball players [12, $21,22]$. It was observed that with the increase in the level of sportsmanship, athletes increased the number of correlation links between different types of preparedness; there are interrelations between those indicators that have not been interconnected previously. This is consistent with the patterns of development of self-organizing systems, whose structure and functioning becomes more complicated and improved as they develop [11, 17, 27]. Since an athlete is a self-organizing system, a high number of interrelated indicators points at a high level of functioning of the organism as a self-organizing system.

In accordance with the indicators included in the $1^{\text {st }}$ factor, we can conclude that the athlete in question has a high-speed

Table 3. The results of repeated testing of the elite athlete with a visual impairment

\begin{tabular}{|c|c|c|c|c|c|c|}
\hline Indicators & $N$ & Minimum & Maximum & & $\mathrm{S}$ & $\mathrm{m}$ \\
\hline Run_100 m (s) & 36 & 11.37 & 13.2 & 12.20 & 0.47 & 0.08 \\
\hline MSE_120 (ms) & 36 & 345 & 400 & 383.31 & 15.21 & 2.53 \\
\hline SVMR (ms) & 36 & 222 & 265 & 238.08 & 11.42 & 1.90 \\
\hline MSE_30 (ms) & 36 & 420 & 452 & 434.22 & 8.71 & 1.45 \\
\hline $\mathrm{ChR}(\mathrm{ms})$ & 36 & 420 & 452 & 435.81 & 9.70 & 1.62 \\
\hline ScT_3 (min) & 36 & 0.35 & 0.69 & 0.52 & 0.10 & 0.02 \\
\hline Run_200 m (s) & 36 & 23.78 & 30.50 & 26.20 & 1.84 & 0.31 \\
\hline MSE_120 (ms) & 36 & 256.00 & 310.00 & 279.56 & 16.27 & 2.71 \\
\hline MSE_30 (ms) & 36 & 59.00 & 70.00 & 66.17 & 3.50 & 0.58 \\
\hline MSE_120_t (s) & 36 & 71.00 & 80.00 & 75.83 & 2.44 & 0.41 \\
\hline
\end{tabular}

Run_100 m - running time at 100 m, MSE_120 - time of the minimum exposure of the signal in the test with feedback at 120 signals (minimum signal exposure), SVMR - time of a simple visual-motor reaction, the average value for one test of 30 signals (time of a simple visual-motor reaction), MSE_30 - time of the minimum exposure of the signal in the test with feedback at 30 signals (minimum signal exposure), ChR - reaction time of the choice of 2 signals of 3 (choice reaction), ScT_3 - time of work on the third table in the Schulte test (Schulte table), Run_200 m - running time at 200 m, MSE_120 - the time to reach the minimum exposure of the signal in the test with feedback at 120 signals, MSE_30 - time of the minimal exposure of the signal in the test with feedback at 30 signals, 
endurance factor, since the $1^{\text {st }}$ factor includes a large number of indicators that reflect the performance of the nervous system [15]. These indicators also reflect the strength of the nervous system, which is somewhat divergent from the literature data, which describe a set of indicators of the nervous system of a sprinter [17, 18], including reaction speed, mobility, and weakness of the nervous system. In literature data [15-18], it is emphasized that the strength of the nervous system is more characteristic of endurance sports.

However, the data obtained by us testify to the ability of the examined athlete to prolong the work of the nervous system, hence, the strength of her nervous system. This may be due to its individual characteristics, as well as the development of compensatory mechanisms associated with the lack of visual analyser. The examined athlete is also characterized by a high ability to develop speed at a distance.

The high efficiency of the nervous system revealed in the examined athlete can also be a compensatory mechanism for the failure of visual function. This confirms the second part of the hypothesis put forward, that athletes with a visual impairment increase the influence of psychophysiological factors as compensatory mechanisms of limited visual possibilities.

The obtained regression models with the involvement of 1-5 psychophysiological indicators also prove the presence of a high degree of influence of psychophysiological indicators on the result in running at $100 \mathrm{~m}$ and $200 \mathrm{~m}$ in the elite athlete. This is evidenced by high values (close to 1 ) of the $\mathrm{R}$-square, as well as high reliability of the regression models obtained and individual coefficients of the regression equations.

In literature data [15-18], it is pointed out that there is a psychophysiological complex of a sprinter characterized by high speed of simple reaction, weakness and mobility of the nervous system. This provision is confirmed by our research only partially. The speed index of a simple visual-motor reaction, which is included in all regression models, really reflects the typical psychophysiological complex of the sprinter. In addition, the minimum signal exposure time in the test for the rate of a complex reaction in feedback mode at 30 signals reflects the mobility of the nervous system [15]. However, the most significant coefficients were also the time index of the minimum exposure of the signal in the test for the rate of a complex reaction in the feedback mode at 120 signals, the total test time for the test of the complex reaction in the feedback mode at 120 signals, the time exponent for the minimum exposure signal in the test with feedback at 120 signals, the time exponent on the third table in the Schulte test. These indicators reflect not only the mobility of the nervous system, but also its ability to work for a long time [15].

This fact contradicts the description of a typical psychophysiological complex of a sprinter [15, 17, 18], since it indicates the ability of the examined athlete to prolong the nervous system and, hence, the strength of her nervous system. This may be due to its individual characteristics, as well as the development of compensatory mechanisms associated with the lack of visual analyser. The examined athlete is also characterized by a high ability to develop speed at a distance. This requires the ability to work and the stability of the nervous system, which is reflected in the high importance of psychophysiological indicators characterizing these qualities $[15,16]$. The high efficiency of the nervous system, revealed in the examined athlete, can also be a compensatory mechanism for the failure of visual function. This confirms the second part of the hypothesis put forward that athletes with visual impairments increase the influence of psychophysiological factors as compensatory mechanisms of limited visual possibilities.

The data obtained supplement the results of studies by Ilin [17, 18], Lyzohub et al. [15], and Korobeynikov et al. [16] on the presence of psychophysiological features in representatives of various sports. For the first time, the influence of psychophysiological indices characterizing the efficiency of the nervous system on the result in running for short distances has been shown. For the first time, theoretical positions have also been formulated on the mechanisms of limiting the speed of running in athletes with visual impairments and possible ways to compensate their limited abilities in sprinting.

The results obtained make it possible to provide the following recommendations for practical work. Since the surveyed athlete is characterized by pronounced mobility of the nervous system and a high speed of simple reaction, in the training process it is expedient to focus on the development of the starting speed and the ability to change the degree of tension and relaxation of the muscles. The examined sportswoman is also characterized by an expressed strength of the nervous system. Therefore, it is needed to concentrate on maintaining speed at a distance for the development of its strong quality, which also acts as a compensation for lack of sight. The development of strengths in the athlete provides additional information to the central nervous system about the movement of the athlete, as a result of which the danger signalling is blocked due to the lack of a visual analyser, and the speed of the athlete's run does not decrease.

It should be noted that in the training process of the examined athlete, these recommendations were taken into account. As a result, at the Paralympic Games in 2016, the athlete showed results that were slightly higher than the forecast based on the regression models, became the World Champion and the silver medallist of the Paralympic Games in 2016.

On the basis of the data obtained, a theoretical concept can be presented on the regulation of running speed in athletes with visual impairments.

According to the theory of functional systems, Anokhin and Shuleikina [27] and Anokhin [28, 29] found that the general scheme of the relationship of running speed and perception of the surrounding space could be represented as follows. The central nervous system receives signals from muscle proprioceptors about the intensity of muscle contractions. At the same time, the central nervous system receives signals from the visual analyser about the surrounding environment. Owing to these signals, the direction of the run is regulated, as well as its speed. If the environmental conditions are relatively stable, as, for example, on a treadmill, the body concentrates its efforts solely on the running speed. If the environmental conditions change, as, for example, when running on rough terrain, in different weather conditions, the speed and direction of the run vary.

If the information from the visual analyser is insufficient, which happens in the case of lack of visual function, the signalling of danger at running is activated in the brain because of this insufficiency of information (Figure 1). As a consequence, the development process of the maximum speed of movement is blocked, which adversely affects the sports result. Athletes with visual impairments are more difficult than healthy athletes to develop the maximum running speed because of the blockage of speed from the central nervous system.

A partial or complete solution of this problem lies in the activation of compensatory mechanisms in the absence of visual function. 


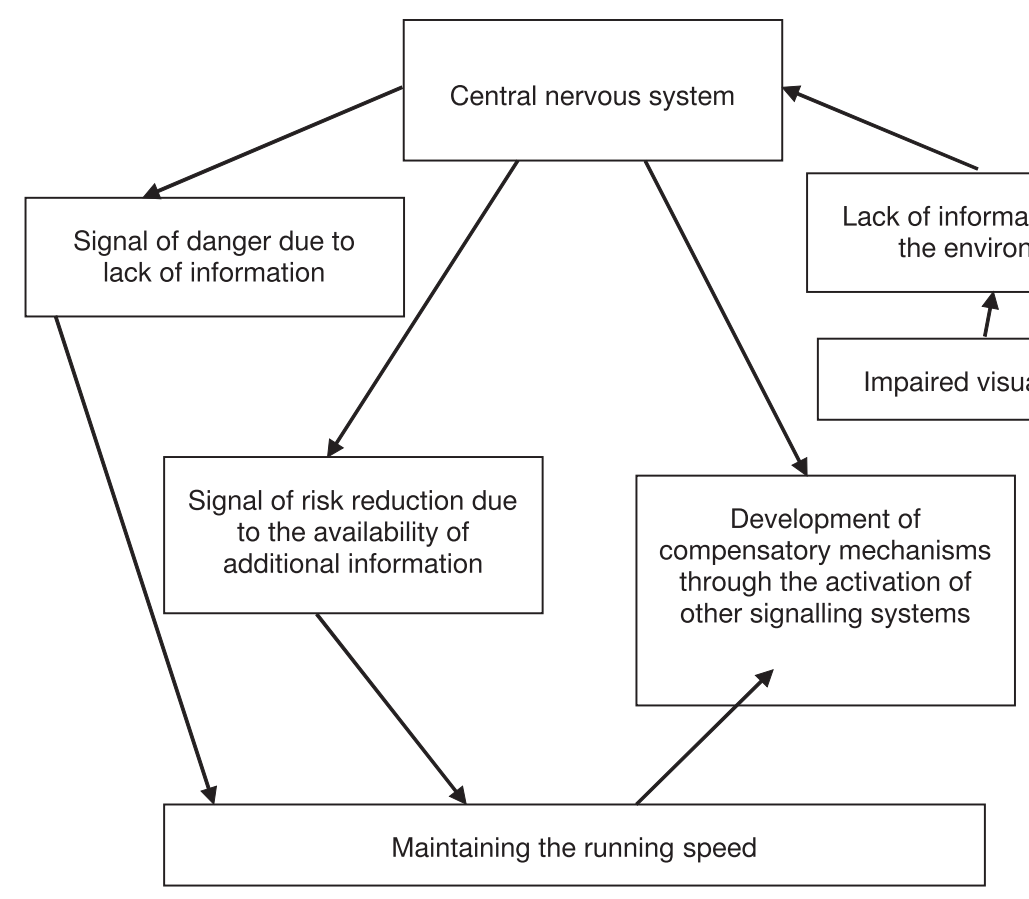

Figure 1. Scheme of compensation for the inadequacy of the visual analyser function in regulating the speed and direction of the run, depending on the visual perception of the surrounding space
Among compensatory mechanisms, there may be an increased perception of signals from the auditory receptors or from the proprioceptors of muscles. Also, athletes with visual impairments may develop such specific feelings as 'track feeling,' 'sense of distance,' etc. to a greater extent than healthy ones. These signals can fully or partially block the danger signals associated with the lack of visual information, and provide the running speed characteristic of the capabilities of the motor apparatus.

It is logical to assume that with the development of psychophysiological functions specific to a particular person, compensatory mechanisms will develop to reduce the lack of visual analyser. Therefore, it is necessary to identify psychophysiological factors associated with running speed. This will enable a deeper understanding of the mechanisms of running speed regulation in people with limited visual function and a more optimal selection of tools and methods for building the training process of sprinters with visual impairments. For example, with pronounced mobility of the nervous system, at a high reaction rate, it is advisable to focus on the development of the starting speed and of the ability to change the degree of muscle tension and relaxation. With the expressed strength of the nervous system, it makes sense to concentrate on maintaining the speed at a distance. The development of strengths in the athlete will give additional information to the central nervous system about the athlete's movement; as a result, the danger signalling will be blocked owing to the lack of a visual analyser, and the speed of the athlete's run will not decrease.

The obtained data supplement the results of studies by Ilin [17, 18], Lyzohub et al. [15], and Korobeynikov et al. [16] on the presence of psychophysiological characteristics of representatives of various sports. For the first time, the influence of psychophysiological indices characterizing the efficiency of the nervous system on the result in running for short distances has been shown. For the first time, theoretical positions have also been formulated on the mechanisms of limiting the speed of running in athletes with visual impairments and possible ways of compensating their limited abilities in sprinting.

\section{Recommendations}

The results obtained make it possible to provide the following recommendations for practical work. Since the surveyed athlete is characterized by pronounced mobility of the nervous system and a high speed of simple reaction, in the training process it is expedient to focus on the development of the starting speed and the ability to change the degree of tension and relaxation of the muscles. The examined sportswoman is also characterized by an expressed strength of the nervous system. Therefore, it is needed to concentrate on maintaining speed at a distance for the development of its strong quality, which also acts as a compensation for lack of sight. The development of strengths in the athlete provides additional information to the central nervous system about the movement of the athlete, as a result of which the danger signalling is blocked due to the lack of a visual analyser, and the speed of the athlete's run does not decrease.

The study proves that athletes with visual impairments develop adaptation mechanisms, which allow to maintain a high running speed. These mechanisms of adaptation are associated with the improvement of the nervous system. The described athlete developed the strength of the nervous system: the ability to withstand strong irritants. This manifested itself in maintaining a high running speed at a distance. This property is more typical of steers. For a sprinter, we regard this as a compensatory mechanism for lack of vision. The experience of the examined athlete can be useful for other athletes with visual impairments and for people with visual impairments who are not athletes.

\section{Limitations}

The study involved only one high-qualified athlete with a visual impairment. The results were obtained by performing multiple measurements. Data were collected bound with the existence of compensatory mechanisms on the part of psychophysiological functions in athletes with visual impairments to maintain the speed of running. These data refer to a particular surveyed athlete but can also spread to 
other elite athletes with visual impairments. However, to confirm these data, studies in large groups of athletes with visual impairments are necessary. Research is also needed on athletes and non-athletes with visual impairments to confirm the compensatory mechanisms identified in this study. Further studies are required to verify these provisions in other sprinters with visual impairments.

\section{Conclusions}

1. Four factors have been singled out in the individual structure of psychophysiological functions and effectiveness in running for short distances in the example of an elite sportswoman with a visual impairment, whose contribution to the total dispersion was $46.4 \%$ for the $1^{\text {st }}$ factor ('Fast work capacity'), $8.2 \%$ for the $2^{\text {nd }}$ factor ('Complicated reaction'), $6.8 \%$ for the $3^{\text {rd }}$ factor ('Attention'), $5.1 \%$ for the $4^{\text {th }}$ factor ('Stability'), 34\% for other factors.

2. A high correlation between psychophysiological indices and performance in running for short distances in an elite athlete with a visual impairment has been shown. The study revealed a high contribution to the individual factor structure of psychophysiological functions and running performance of indicators reflecting the qualities characteristic of sprinters (speed of reaction and mobility of the nervous system) and nonspecific for sprinters (working capacity and strength of the nervous system).

3 . The models of multiple linear regression between the results in running at $100 \mathrm{~m}$ and $200 \mathrm{~m}$ in the elite athlete with a visual impairment and psychophysiological indices are provided. Compensatory mechanisms of visual deficiency have been identified to maintain high speed in short-distance running as psychophysiological functions: indicators characteristic of sprinters (speed of simple reaction and motility of the nervous system) and specific indicators (efficiency, strength of the nervous system).

\section{Acknowledgements}

The study was conducted in accordance with the research work of Ministry of Education and Science of Ukraine for 2017-2018 'Theoretical and methodical bases of application of information, medical, biological, and pedagogical technologies for implementation of individual physical, intellectual, and spiritual potential and formation of a healthy lifestyle' (state registration No., 0117U000650).

\section{Disclosure statement}

No author has any financial interest or received any financial benefit from this research.

\section{Conflict of interest}

The authors state no conflict of interest.

\section{References}

1. Cacioppo J, Tassinary LG, Berntson GG. The handbook of psychophysiology, $3^{\text {rd }}$ ed. New York: Cambridge University Press; 2007.

2. Glynn LM, Christenfeld N, Gerin W. The role of rumination in recovery from reactivity: cardiovascular consequences of emotional states. Psychosom Med. 2002;64(5): 714-726; doi: 10.1097/01.PSY.0000031574.42041.23.

3. Hussain MS, AlZoubi O, Calvo RA, D'Mello SK. Affect detection from multichannel physiology during learning sessions with AutoTutor. In: Biswas G, Bull S, Kay J,
Mitrovic A (eds.), Artificial intelligence in education. AIED 2011. Berlin, Heidelberg: Springer; 2011; 131-138.

4. Stemmler G, Wacker J. Personality, emotion, and individual differences in physiological responses. Biol Psychol. 2010;84(3):541-551; doi: 10.1016/j.biopsycho.2009. 09.012 .

5. Gross CT, Canteras NS. The many paths to fear. Nat Rev Neurosci. 2012;13(9):651-658; doi: 10.1038/nrn3301.

6. Bos MW, Dijksterhuis A, van Baaren R. Food for thought? Trust your unconscious when energy is low. J Neurosci Psychol Econ. 2012;5(2):124-130; doi: 10.1037/a0027388.

7. Greenland K, Xenias D, Maio G. Intergroup anxiety from the self and other: evidence from self-report, physiological effects, and real interactions. Eur J Soc Psychol. 2012;42(2):150-163; doi: 10.1002/ejsp.867.

8. Kakarot N, Mueller F, Bassarak C. Activity-rest schedules in physically demanding work and the variation of responses with age. Ergonomics. 2012;55(3):282-294; doi: 10.1080/00140139.2011.639906.

9. Kircanski K, Mortazavi A, Castriotta N, Baker AS, Mystkowski JL, Yi R, et al. Challenges to the traditional exposure paradigm: variability in exposure therapy for contamination fears. J Behav Ther Exp Psychiatry. 2012;43(2): 745-751; doi: 10.1016/j.jbtep.2011.10.010.

10. Chaika OI, Kozina ZL, Korobeynik VA, Bazylyuk TA. Individual structure of psychophysiological functions in connection with competitive performance in the Paralympic sprint on the example of a high-skilled student with visual impairment [in Russian]. Health, Sport, Rehabilitation. 2018;4(1):96-107; doi:10.5281/zenodo.1218585.

11. Kalinicenko VE, Kozina ZL, Ahmad MA, Polishchuk SB, Chuprina OI, Seryy AV, et al. Musical accompaniment in training as a factor in optimizing the psychophysiological state of young rugby players aged 16-17 years. Health, Sport, Rehabilitation. 2018;4(1):49-59; doi: 10.5281/zenodo.1218559.

12. Kozina Z, Sobko I, Yermakova T, Cieslicka M, Zukow W, Chia $M$, et al. Psycho-physiological characteristics of female basketball players with hearing problems as the basis for the technical tactic training methodic in world level teams. J Phys Educ Sport. 2016;16(4):1348-1359; doi: 10.7752/jpes.2016.04213.

13. Kozina Z, Shepelenko T, Cieślicka M, Prusik K, Muszkieta R, Osiptsov A, et al. The teams' formation in sport aerobics on the basis of application of multidimensional analysis methods. Phys Educ Students. 2017;21(6): 270-279; doi: 10.15561/20755279.2017.0603.

14. Korobeynikov GV, Korobeynikova LG, Romanyuk LV, Dakal NA, Danko GV. Relationship of psychophysiological characteristics with different levels of motivation in judo athletes of high qualification. Pedagog Psychol MedBiol Probl Phys Train Sports. 2017;21(6):272-278; doi: 10.15561/18189172.2017.0603.

15. Lyzohub V, Nechyporenko L, Pustovalov V, Suprunovych V. Specialized training and bioenergy state of football players with different typological properties of the higher parts of the nervous system. Science and Education. 2016;8:107-112; doi: 10.24195/2414-4665-20168-21.

16. Korobeynikov G, Mazmanian K, Korobeynikova L, Jagiełło W. Psychophysiological states and motivation in elite judokas. Archives of Budo. 2010;6(3):129-136.

17. Ilin EP. Differential psychophysiology, its place and role in the study of the personality of athletes [in Russian]. Sportivnaya i Vozrastnaya Psihofiziologiya. 1974;1:5-24. 
18. Ilin EP. The strength of the nervous system and the methods of its investigation [in Russian]. Psihofiziologicheskie Osnovyi Fizicheskogo Vospitaniya i Sporta. 1972;1:5-12.

19. Brazil A, Exell T, Wilson C, Willwacher S, Bezodis I, Irwin G. Lower limb joint kinetics in the starting blocks and first stance in athletic sprinting. J Sports Sci. 2017;35(16): 1629-1635; doi: 10.1080/02640414.2016.1227465.

20. Znazen H, Slimani M, Miarka B, Butovskaya M, Siala H, Messaoud T, et al. Mental skills comparison between elite sprint and endurance track and field runners according to their genetic polymorphism: a pilot study. J Sports Med Phys Fitness. 2017;57(9):1217-1226; doi: 10.23736/S0022-4707.16.06441-0.

21. Kozina Z, lermakov S, Crełu M, Kadutskaya L, Sobyanin F. Physiological and subjective indicators of reaction to physical load of female basketball players with different game roles. J Phys Educ Sport. 2017;17(1):378382; doi: 10.7752/jpes.2017.01056.

22. Kozina Z, Prusik K, Görner K, Sobko I, Repko O, Bazilyuk T, et al. Comparative characteristics of psychophysiological indicators in the representatives of cyclic and game sports. J Phys Educ Sport. 2017;17(2):648-655; doi: 10.7752/jpes.2017.02097.

23. Blecharz J, Siekanska M. Temperament structure and ways of coping with stress among professional soccer and basketball players. Biol Sport. 2007;24(2):143156.

24. Boldak A, Guszkowska M. Are skydivers a homogenous group? Analysis of features of temperament, sensation seeking, and risk taking. Int J Aviat Psychol. 2013;23(3): 197-212; doi: 10.1080/10508414.2013.799342.

25. Chen Y, Zhou AQ, Qian GR, Gong XQ. Pre-competition psychological training of middle school athletes in middle and long distance race from the perspective of temperament type - case study. Proceedings of the Xi'an 2012 International Conference of Sport Science \& Physical Education, vol. 2: Physical education and innovation; 2012; 177-181.

26. Fagher K, Forsberg A, Jacobsson J, Timpka T, Dahlström Ö, Lexell J. Paralympic athletes' perceptions of their experiences of sports-related injuries, risk factors and preventive possibilities. Eur J Sport Sci. 2016;16(8): 1240-1249; doi: 10.1080/17461391.2016.1192689.

27. Anokhin PK, Shuleikina KV. System organization of alimentary behavior in the newborn and the developing cat. Dev Psychobiol. 1977;10(5):385-419; doi: 10.1002/dev. 420100502.

28. Anokhin PK. Systemogenesis as a general regulator of brain development. Progress Brain Res. 1964;9:54-86; doi: 10.1016/S0079-6123(08)63131-3.

29. Anokhin PK. Biology and neurophysiology of the conditioned reflex and its role in adaptive behavior. Oxford: Pergamon Press; 1974. 